\title{
Análise do Processo de Gelificação de Resinas e Compostos de PVC Suspensão
}

\author{
Juliana P. D. Alves \\ PPG-CEM, UFSCar \\ Antonio Rodolfo Jr. \\ Braskem S/A
}

\begin{abstract}
Resumo: Este artigo busca analisar a relação existente entre o grau de gelificação de compostos de PVC rígido (U-PVC) durante seu processamento e as propriedades mecânicas finais dos produtos obtidos através do processo de extrusão de tubos. Para tanto, a morfologia das resinas de PVC é analisada a fim de se entender seu desenvolvimento ao longo da extrusão e entender sua influência na gelificação já que o desempenho do produto dependerá dessa influência. O desenvolvimento morfológico, devido às condições de processamento e ambiente termo-mecânico, bem como alguns testes como microscopia eletrônica de varredura para monitorar esse desenvolvimento são descritos. O grau de gelificação e sua quantificação são analisados utilizando reometrias de torque, rotacional e capilar, utilizando análises térmicas (DSC) e utilizando imersão em solvente (cloreto de metileno).
\end{abstract}

Palavras-chave: $P V C$, poli(cloreto de vinila), grau de gelificação, morfologia, resina de suspensão, processo de extrusão.

\section{Analisys of the Gelation Process of Suspension PVC Resins and Compounds}

Abstract: This paper analyses the relation between the degree of gelation of rigid unplasticised PVC compounds (U-PVC) and the mechanical properties of final products made of them. The morphology of PVC resins is analyzed in order to understand its development during the extrusion process and the influence in the gelation process, once the performance of the final product depends of it. The morphological development, the processing conditions, the thermal-mechanical environment and some techniques for its determination, such as scanning electron microscopy, are described. The degree of gelation and its quantification are determined using torque, rotational and capillary rheometry, differential scanning calorimetry (DSC) and solvent immersion (dichloromethane).

Keywords: PVC, poly(vinyl chloride), degree of gelation,morphology, suspension resin, extrusion process.

\section{Introdução}

A boa resistência à propagação de chama, às intempéries, a baixa permeabilidade, a boa isolação térmica, elétrica e acústica, a boa processabilidade, a reciclabilidade adequada e a versatilidade assegurada através de seus compostos, fazem do PVC um polímero apropriado para diversas aplicações cujos processos de fabricação utilizam calandragem, extrusão, moldagem a sopro, extrusão de tubos flexíveis e rígidos, cabos e moldagem por injeção.

A partir da metade do século XX, PVC rígido tornou-se um dos termoplásticos mais importantes usados na fabricação de tubos para a construção civil ${ }^{[1]}$. Devido sua excelente resistência química e a corrosão, juntamente com sua alta resistência mecânica e dureza adequada fizeram do PVC um material excelente para fabricação de dutos utilizados no transporte de água e escoamento de esgoto. Esta aplicação utiliza formulações de PVC extrudadas na forma de tubos em diversos diâmetros e espessuras.
Para a extrusão desses tubos, a resina de PVC mais utilizada é a de suspensão juntamente com diversos aditivos tais como estabilizantes, cargas, auxiliares de processamento obtendo-se um composto de PVC denominado de dry-blend (mistura seca).

\section{Morfologia da resina de PVC tipo suspensão}

A resina de PVC do tipo suspensão se apresenta na forma de pó, após o seu processo de síntese, e mostra uma estrutura de partículas um tanto quanto complexa ${ }^{[2]} \mathrm{com}$ reduzido grau de cristalinidade: de 5 a $10 \%$. Sua morfologia de partículas é apresentada esquematicamente na Figura 1.

A resina é constituída de grãos, ou seja, partículas granulares, cujo tamanho varia em média entre 100 a $150 \mu \mathrm{m}$; por sua vez, cada grão é constituído por inúmeras partículas denominadas partículas primárias cujo tamanho varia de 1 a $2 \mu \mathrm{m}$. As partículas primárias, por sua vez, são compostas por domínios cujo tamanho varia entre 100 a $300 \AA$, que são formados a partir de regiões cristalinas, constituídas

Autor para correspondência: Juliana P. D. Alves, Programa de Pós-Graduação em Ciência e Engenharia de Materiais - PPG-CEM, UFSCar , Via Washington Luís, km 235, Caixa Postal 676, CEP: 13565-905, São Carlos, SP. E-mail: julianapda@yahoo.com.br 


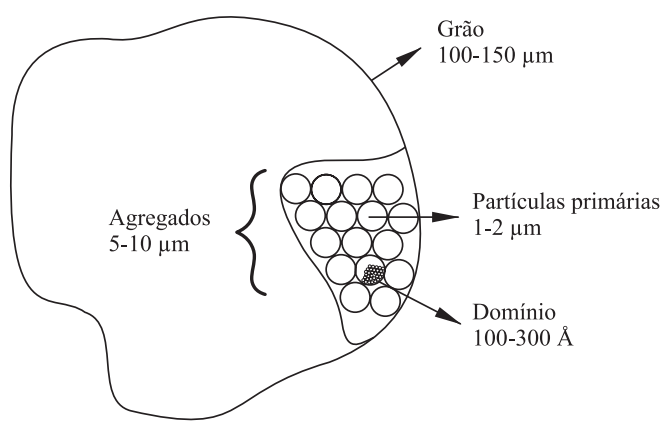

Figura 1. Estrutura morfológica das partículas da resina de suspensão de PVC

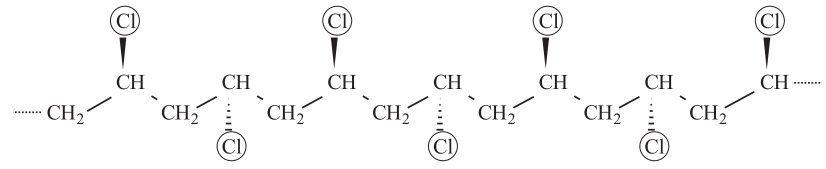

Figura 2. Representação de parte da cadeia molecular do PVC encontradas nos domínios dos grãos.

de estruturas lamelares de cadeias sindiotáticas cujos tamanhos variam de 50 a $100 \AA$, interconectadas por segmentos de cadeias desordenadas da região amorfa. Portanto, o menor nível estrutural dos grãos inclui zonas compostas por segmentos de cadeia sindiotáticos, onde os átomos de cloro se situam de forma alternada em relação à cadeia principal, como ilustrado na Figura 2.

Os grãos da resina de suspensão apresentam uma superfície rugosa e irregular devido aos aglomerados ou agregados de partículas primárias ${ }^{[2]}$. Na fotomicrografia apresentada na Figura 3, obtida através de microscopia eletrônica de varredura (MEV), esta rugosidade pode ser visualizada de maneira clara. Nesta figura encontra-se uma barra inserida na micrografia cujo comprimento corresponde a $200 \mu \mathrm{m}$. Desta forma é possível observar a ordem de grandeza de tamanho médio dos grãos da resina de suspensão de PVC. A porosidade presente nos grãos da resina de suspensão se deve aos espaços vazios presentes entre os aglomerados de partículas primárias. Isto também é possível de ser observado através de MEV, conforme pode ser observado na Figura 4.

\section{Gelificação e grau de gelificação da resina de PVC}

As resinas de PVC sofrem um processo de gelificação e fusão quando aquecidas durante seu processamento ou sua transformação em produto, através de extrusão, calandragem, moldagem por injeção, etc. Esta resina apresenta algumas peculiaridades que tornam seu mecanismo de fusão ou de plastificação diferente da maioria dos termoplásticos. Antes de ocorrer à fusão completa da resina de PVC durante seu processamento, uma etapa conhecida como gelificação acontece e é fundamental para que a resina de PVC torne-se uma massa fundida e processável.

As condições de operação bem com o ambiente termomecânico gerado durante o processamento tendem a modificar a estrutura de partículas granulares descrita anteriormente. A identidade dos grãos, das partículas primárias bem como a região cristalina é destruída durante o processo de gelificação

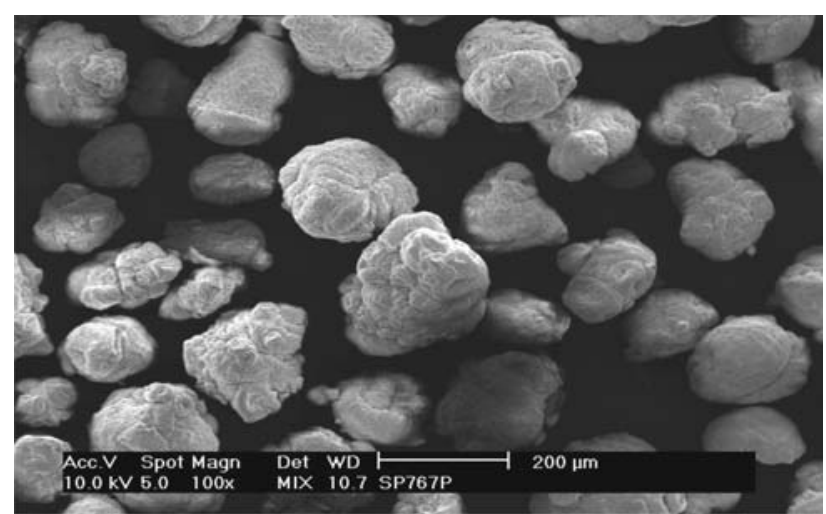

Figura 3. Micrografia da resina de suspensão de PVC obtida através de microscopia eletrônica de varredura (MEV).

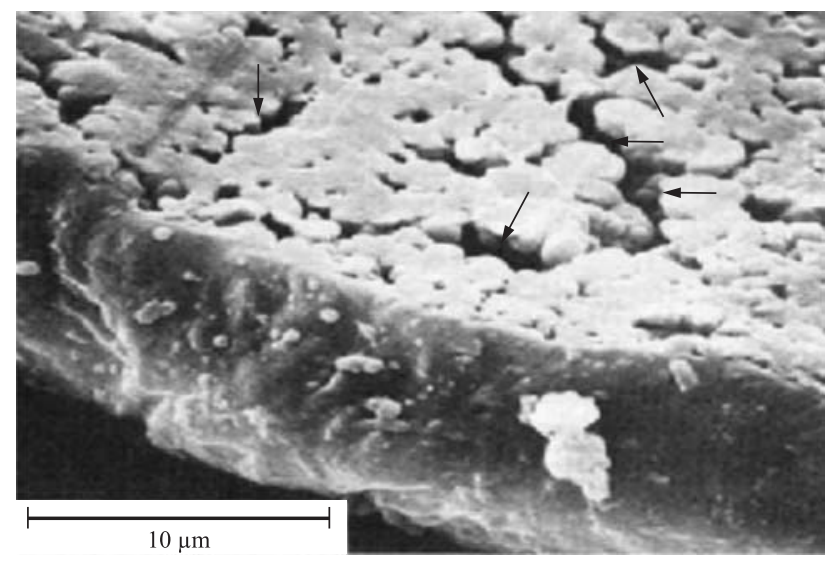

Figura 4. Micrografia da estrutura interna do grão de resina de suspensão de PVC obtida por microscopia eletrônica de varredura.

e fusão. Por outro lado, o resfriamento realizado após a fusão proporciona a formação de uma rede tridimensional de cadeias emaranhadas e com regiões ordenadas. Este fenômeno é denominado Cristalização Secundária cujos cristais são menos perfeitos que aqueles obtidos durante a formação de domínios originais. Assim, a resina de suspensão de PVC perde suas características morfológicas após seu primeiro processamento, ou seja, sua primeira plastificação no estado fundido. A resina processada passa a ter uma morfologia completamente diferente daquela original.

O processo de gelificação deve ser descrito como uma desintegração de vários níveis morfológicos através da combinação de temperatura, pressão e tensão local acompanhado pelo desenvolvimento de um fundido mais ou menos homogêneo e com o resfriamento o desenvolvimento de uma cristalização secundária.

A relação entre os parâmetros de processamento e as propriedades do produto final tem sido estudada largamente. A principal conclusão obtida é que o processo de gelificação é o principal elo entre as condições de processamento e as propriedades mecânicas do produto transformado ${ }^{[1]}$. O grau de gelificação é um parâmetro muito importante já que pelo seu controle, este irá influenciar de maneira significativa as propriedades mecânicas do produto final ${ }^{[3]}$.

Allsopp ${ }^{[4]}$ sugere que em equipamentos industriais tais como as extrusoras de rosca dupla, o mecanismo de fusão 
inclui compactação (C), densificação (D), fusão (F) e elongação (E) dos grãos de PVC, mecanismo conhecido como CDFE, com muito pouco ou nenhum grão moído. Inicialmente, os grãos são compactados, densificados e sua porosidade interna é progressivamente eliminada com aumento da pressão e da temperatura, então se inicia um processo de fusão intra-granular, ou seja, dentro de cada grão.

Como mencionado acima, o grau de gelificação influencia fortemente nas propriedades físicas e mecânicas do material extrudado. Porém, não é necessário atingir o máximo grau de gelificação para que o material processado atinja os máximos valores de propriedades. Por exemplo, produtos de PVC podem apresentar ótimo desempenho mecânico com graus de gelificação não muito elevados. Para uma formulação típica, um desempenho ótimo pode ser obtido com graus de gelificação entre 60 e 70\%.

Geralmente, propriedades relacionadas com resistência como tensão máxima e elongação na ruptura aumentam com o grau de gelificação até atingir um valor máximo ${ }^{[2]}$, ou seja, existe um valor ótimo para certo grau de gelificação. Este fenômeno pode também ser observado através da resistência ao impacto Charpy, conforme ilustrado na Figura 5.

Durante o ensaio de impacto de compostos de PVC a tensão aplicada provoca a formação de pequenos vazios estruturais entre as partículas primárias remanescentes do processo de gelificação e fusão, sendo que estes pequenos vazios estruturais ajudam a dissipar as tensões aplicadas ${ }^{[5]}$. Porém, se o grau de gelificação do composto de PVC é baixo, as tensões aplicadas podem ser suficientes para separar as partículas primárias, uma vez que a ligação entre as mesmas é fraca, fazendo com que o material sofra fratura com facilidade apresentando baixa resistência ao impacto.

No grau de gelificação ótimo, as partículas primárias remanescentes do processo de gelificação e fusão apresentam o máximo grau de coesão, com forças de ligação extremamente fortes, persistindo na estrutura interna do composto os pequenos vazios estruturais que atuam com aliviadores, porém neste caso as forças de ligação são capazes de resistir à tensão aplicada, elevando a resistência ao impacto para um máximo.

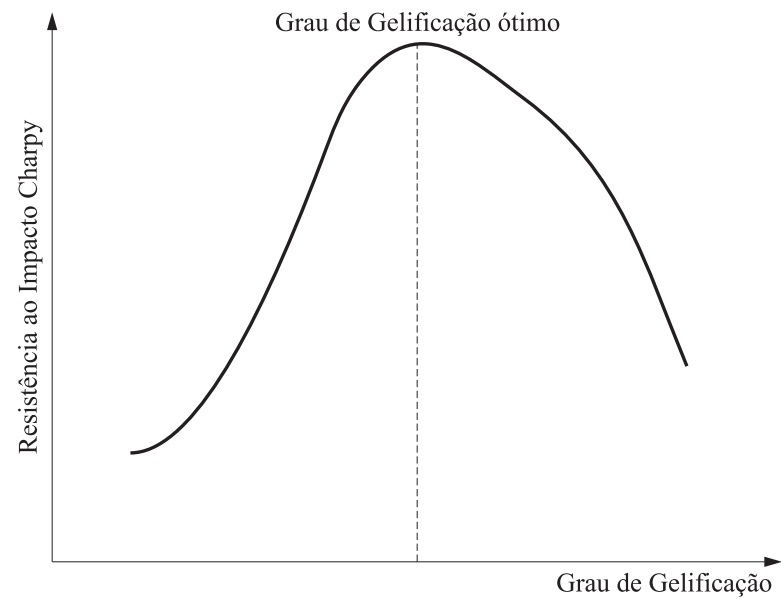

Figura 5. Curva da resistência ao impacto para um composto de PVC rígido em função do grau de gelificação obtido no processamento.
Para valores acima do grau de gelificação ótimo tem-se uma matriz vítrea de PVC sem vazios estruturais. Neste caso, o mecanismo de alívio de tensões não ocorre e o composto rompe-se de forma frágil devido à concentração de tensões e propagação facilitada da fratura, apresentando o composto baixa resistência ao impacto. Por outro lado, parâmetros como tensão e elongação no escoamento são independentes do grau de gelificação ${ }^{[2]}$.

\section{Análise da evolução morfológica durante o processo de gelificação e fusão da resina de PVC tipo suspensão}

Como já mencionado anteriormente, as condições de processamento bem como o ambiente termo-mecânico desenvolvido durante o processo de extrusão tendem a modificar a estrutura morfológica inicial da resina de PVC. O desempenho da resina depende do entendimento da influência da sua particular morfologia na evolução da gelificação durante o processamento.

Para analisar a influência da morfologia na gelificação, existem técnicas capazes de monitorar a evolução da morfologia e o comportamento de gelificação e fusão como exemplos, a reometria de torque, a microscopia eletrônica de varredura e a microscopia ótica com luz polarizada.

Covas ${ }^{[2]}$ analisou o processo de gelificação de compostos de PVC durante sua extrusão através de rosca-dupla. Para analisar o desenvolvimento morfológico durante a gelificação utilizou uma extrusora especial, desenvolvida na Universidade do Minho, ou seja, uma extrusora de rosca dupla contra-rotacional Leistritz AG LSM 36/25D, com uma série de orifícios ao longo do barril da extrusora possibilitando a coleta de amostras do material em locais específicos do comprimento da rosca durante o processo de extrusão, mantidas as condições de processo constantes.

O desenvolvimento morfológico das amostras retiradas ao longo do barril durante o processo de extrusão foi observado com o auxílio de um microscópio eletrônico de varredura (MEV) e observou-se um mecanismo de gelificação semelhante ao observado por Allsopp ${ }^{[4]}$, ou seja, o mecanismo conhecido como CDFE que envolve primeiramente a compactação, densificação, fusão e elongação dos grãos de PVC, com muito pouca ou nenhuma quebra de grãos.

\section{Reometria de torque}

O comportamento da gelificação e fusão de resinas e compostos de PVC podem ser estudados através da realização do ensaio em reometria de torque ${ }^{[5]}$. O uso de um reômetro de torque permite observar as dependências do tempo, variação do torque e de temperatura, necessário para caracterizar o progresso do processo de gelificação do $\mathrm{PVC}^{[6]}$.

A influência da composição no processo de gelificação pode ser determinada através da análise dos parâmetros medidos, e da dependência do tempo nas mudanças do comportamento do composto de PVC. À medida que o composto é alimentado ainda sólido na câmara do reômetro, ocorre um aumento significativo nos valores de torque, seguida de uma diminuição do mesmo até um valor mínimo devido à deformação dos grãos. 


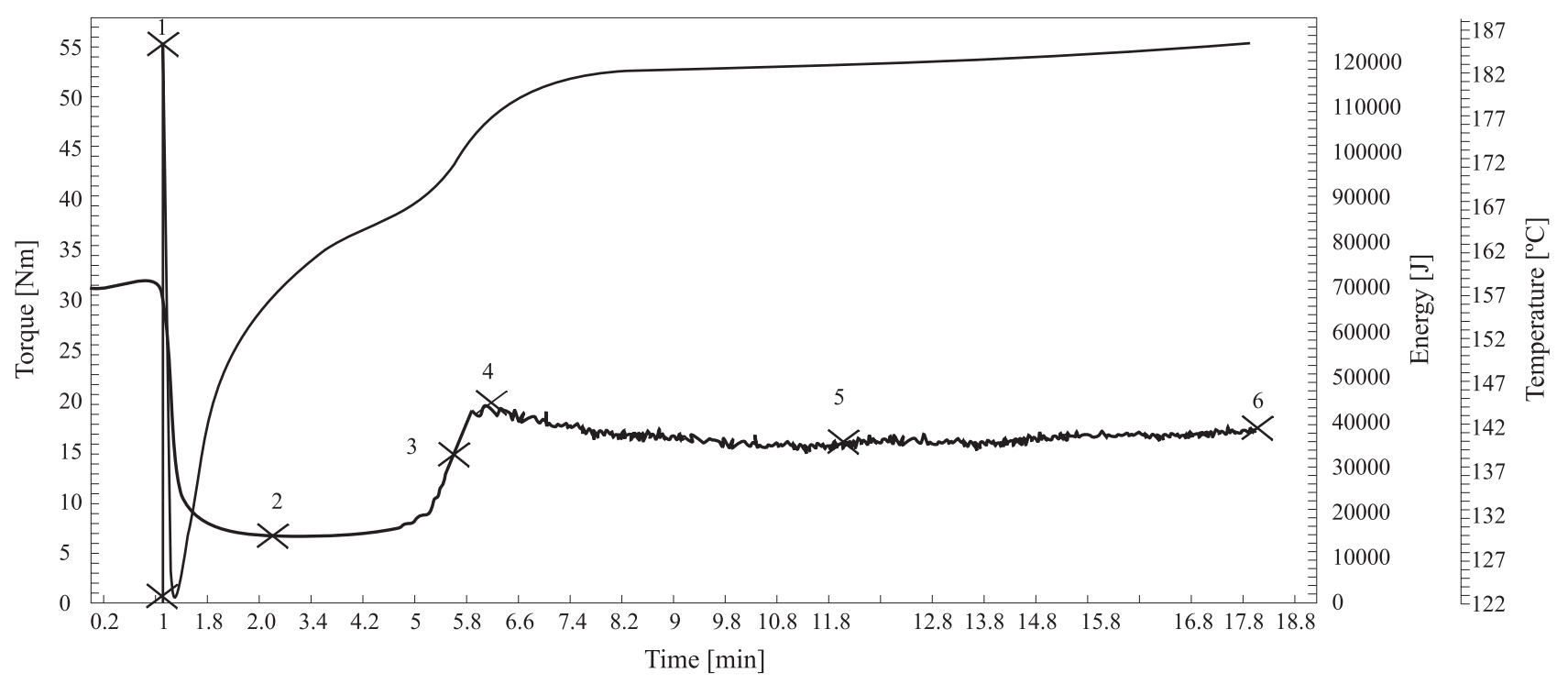

Figura 6. Resultado típico obtido através da análise do comportamente de gelificação e fusão de compostos de PVC rígido no reômetro de torque

O comportamento morfológico durante ensaio em um reômetro de torque é diferente do observado em uma extrusora, devido às condições impostas pelo reômetro de torque. No reômetro de torque ocorre primeiramente uma quebra das partículas exibindo um aglomerado de partículas primárias. Logo depois se observa que estas partículas se separam umas das outras, e o processo de interdifusão das cadeias poliméricas começa a ocorrer ${ }^{[2]}$.

A Figura 6 exibe a curva típica obtida como resultado da avaliação de uma amostra via reometria de torque. A análise permite monitorar ao mesmo tempo parâmetros como a variação de temperatura em função do tempo de ensaio, a variação de energia mecânica transferida pelols rotores ao material ao longo do tempo de ensaio e a variação do torque durante o tempo de ensaio.

Os pontos de 1 a 6 da curva da Figura 6 indicam o momento em que as amostras foram retiradas para subseqüente análise morfológica com o auxílio de um microscópio eletrônico de varredura (MEV). Para tanto, fez-se necessário a realização de uma série de ensaios no reômetro de torque terminando o ensaio nos pontos que se queriam retirar as amostras.

Na curva de torque versus tempo, o ponto 1, chamado de pico de carregamento, representa o torque máximo registrado quando o composto entra na câmara do reômetro ocorrendo uma compressão e densificação dos grãos iniciais da resina.

Posteriormente, uma redução no torque é observada devido a deformação dos grãos em uma temperatura acima da temperatura de transição vítrea da resina de PVC, ou seja, em torno de $80^{\circ} \mathrm{C}$. No ponto número 2 da curva inicia-se o processo de gelificação. A estrutura granular começa a ser parcialmente destruída ocorrendo à quebra dos grãos em partículas primárias, o que oferece uma resistência menor para os rotores do reômetro, reduzindo assim os valores de torque a um míni$\mathrm{mo}^{[2]}$. Com a aplicação progressiva de cisalhamento sob calor as partículas sofrem um novo processo de densificação formando um estado de gel homogêneo ${ }^{[5]}$. As forças de interação entre as partículas são fracas nesta situação, ou seja, a conso- lidação do composto na forma de um material coeso ainda não ocorreu e o modo de fluxo predominante é o fluxo particulado, apesar de haver um pequeno grau de interdifusão de macromoléculas na superfície das partículas ${ }^{[5]}$.

A partir deste ponto, a fusão do composto se inicia o que provoca um aumento do torque, sendo que a partir do ponto 4 ocorre o pico de fusão onde o composto encontra-se fundido.

Prosseguindo com a aplicação de cisalhamento sob calor, as partículas primárias em temperaturas entre $180^{\circ} \mathrm{C}$ e $210^{\circ} \mathrm{C}$ (dependendo do peso molecular da resina) sofrem um processo de fusão intra-granular sendo os limites entre as partículas primárias destruídas. O ponto 4 da curva torque $v s$ tempo chama-se pico de fusão e neste ponto o composto encontrase fundido.

A partir desse pico, a viscosidade diminui, devido a um aumento na temperatura e também devido ao alto grau de homogeneização do composto fundido. Nos pontos 5 e 6 , a temperatura e a viscosidade atingem valores constantes, sendo portanto denominado de torque de equilíbrio.

Apesar de não estar sendo representado na curva, a partir do ponto 6, o composto começa a degradar, ocorrendo o mecanismo de reticulação o que provoca um aumento final da viscosidade e conseqüentemente do torque.

\section{Microscopia eletrônica de varredura (MEV)}

A caracterização morfológica pode ser realizada utilizando-se um microscópio eletrônico de varredura (MEV), após a retirada de amostras durante a análise no reômetro de torque e na extrusora. A Figura 7 apresenta micrografias obtidas através de MEV de amostras que foram retiradas nos pontos indicados na curva da Figura 6.

A micrografia "a" da Figura 7 representa o ponto 1 da curva torque versus tempo da Figura 6, no qual ocorre uma compressão e densificação dos grãos iniciais da resina. A micrografia "b", por sua vez, representa o ponto 2 da mesma curva, no qual inicia-se o processo de gelificação do composto de PVC. A micrografia "c" representa o ponto 4 da 

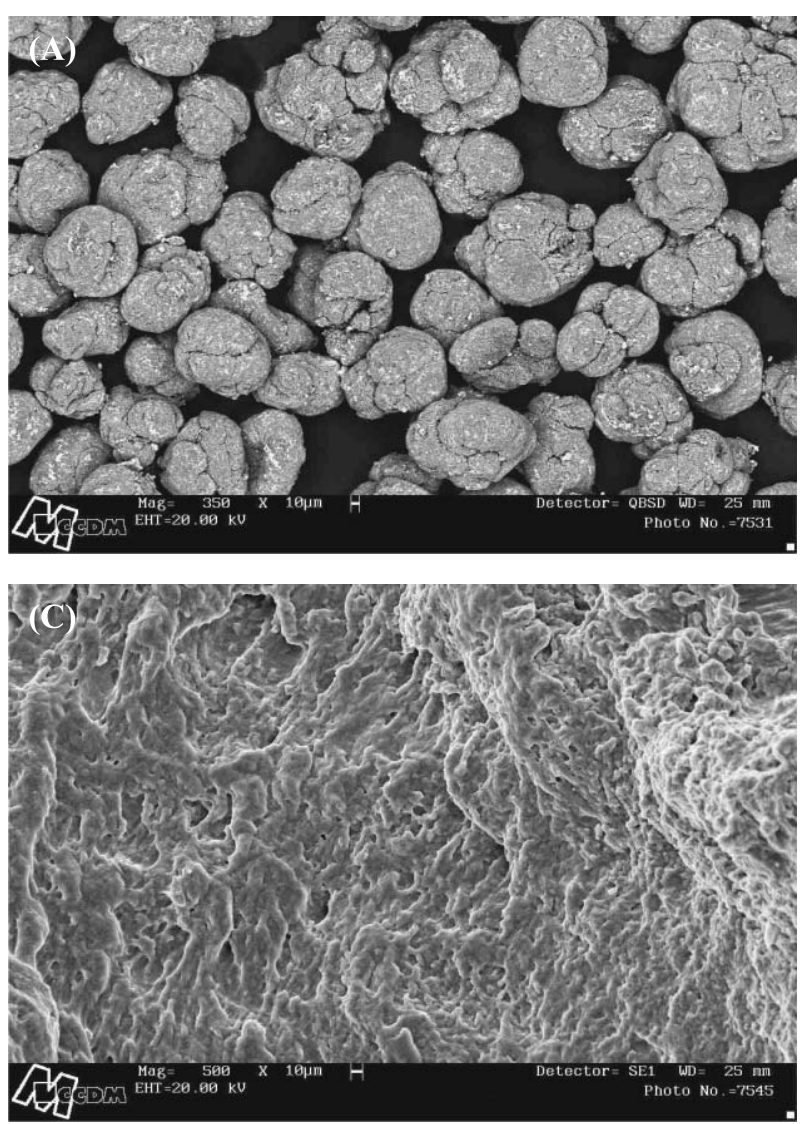
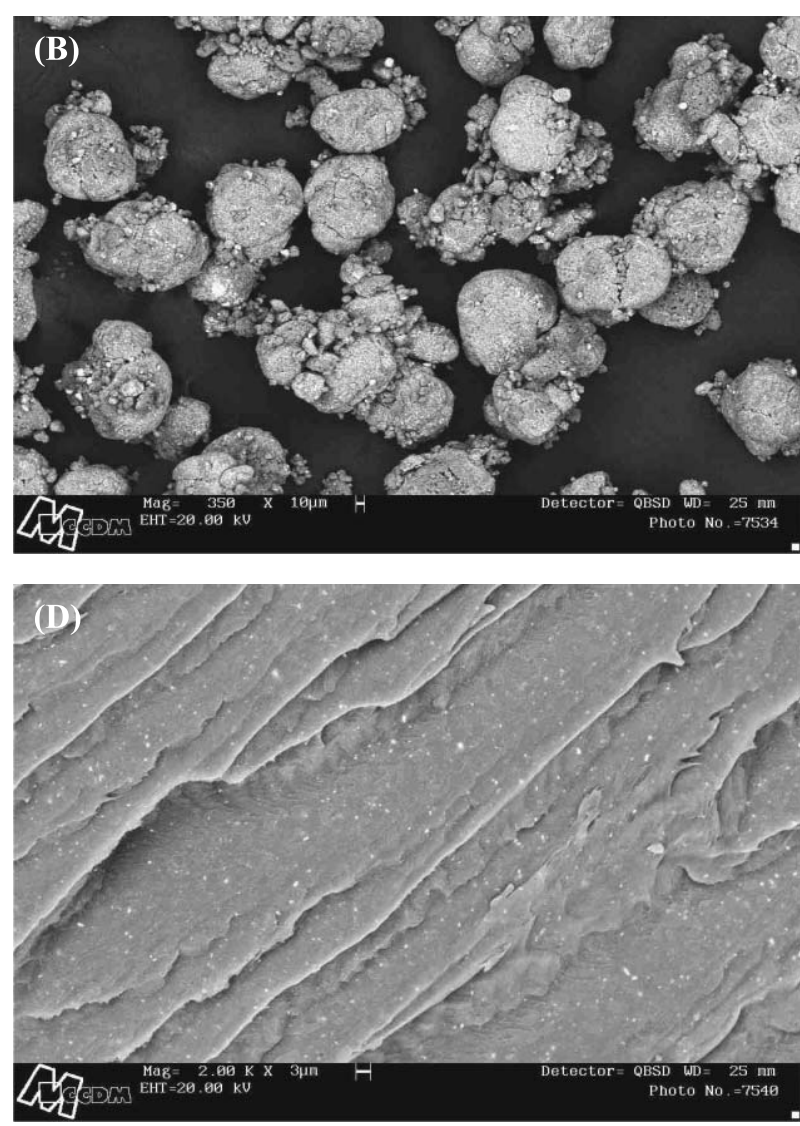

Figura 7. Variação morfológica observada através de MEV para amostras retiradas durante ensaio no reômetro de torque mostrado na Figura 6: (a) amostra correspondente ao ponto 1; (b) amostra correspondente ao ponto 2; (c) amostra correspondente ao ponto 4; (d) amostra correspondente ao ponto 5.

curva, no qual o composto de PVC gelificado inicia o processo de interdifusão das partículas primárias. E, finalmente, a micrografia "d" representa o ponto 5 da curva, no qual o composto de PVC encontra-se completamente fundido.

\section{Determinação do grau de gelificação}

Existem técnicas de ensaio que podem direta ou indiretamente serem utilizadas para a caracterização do grau de gelificação do PVC. Microscopias eletrônica e ótica, análise de calorimetria exploratória de varredura (DSC), propriedades reológicas, absorção de solventes e avaliação de propriedades mecânicas são as principais técnicas utilizadas para esse fim ${ }^{[6]}$.

\section{Uso de calorimetria exploratória diferencial (DSC) para determinação do grau de gelificação}

A técnica de DSC mede o fluxo de calor quando a amostra é submetida a um programa de temperatura, ou seja, submetida a aquecimento ou resfriamento. O calor absorvido (endotérmico) ou liberado (exotérmico) pela amostra é registrado através de um termograma ${ }^{[7]}$.

As transições térmicas decorrentes de alterações físicas e químicas que ocorrem durante o aquecimento ou o resfriamento da amostra estão relacionadas com a perda ou ganho de energia ou com mudanças na capacidade calorífica específica da amostra.

As transições são, geralmente, observadas através de pi- cos ou degraus na curva do termograma obtido. A integração do pico, ou seja, a área sob o pico, fornece a energia necessária para a transição.

Quando um composto de PVC tipo suspensão não processado (não foi submetido ao processo de extrusão) é caracterizado através de DSC, uma ampla faixa endotérmica entre 140 e $150^{\circ} \mathrm{C}$ até $230^{\circ} \mathrm{C}$ é obtida, podendo este comportamento ser observado na Figura 8 que representa termograma de DSC obtido para um composto de PVC não processado. Esta região endotérmica é atribuída à fusão das regiões ordenadas ou cristalinas que equivale a aproximadamente $10 \%$ do peso molecular do $\mathrm{PVC}^{[8]}$. A temperatura de fusão ampla indica uma grande dispersão de tamanhos de cristalitos e graus variados de perfeição. Temperaturas de processamento padrão, como por exemplo, entre 180 e $200{ }^{\circ} \mathrm{C}$ para extrusão, não são altas suficiente para fundir todos os cristalitos. Apenas uma fusão parcial ocorre. A parte cristalina que se fundiu pode se recristalizar durante o resfriamento, e uma nova ordem cristalina pode ser criada denominada “cristalização secundária”, além daquela proporcionada pelos cristais que não fundiram durante o processamento, denominados como cristais primários.

Gilbert e Vyvoda ${ }^{[9]}$ foram os primeiros a identificar dois picos endotérmicos para compostos de PVC processados, ou seja, que foram submetidos ao processo de extrusão. Estes picos são ilustrados como A e B na Figura 9, e representam o comportamento complexo de fusão para compostos de PVC já processados. 


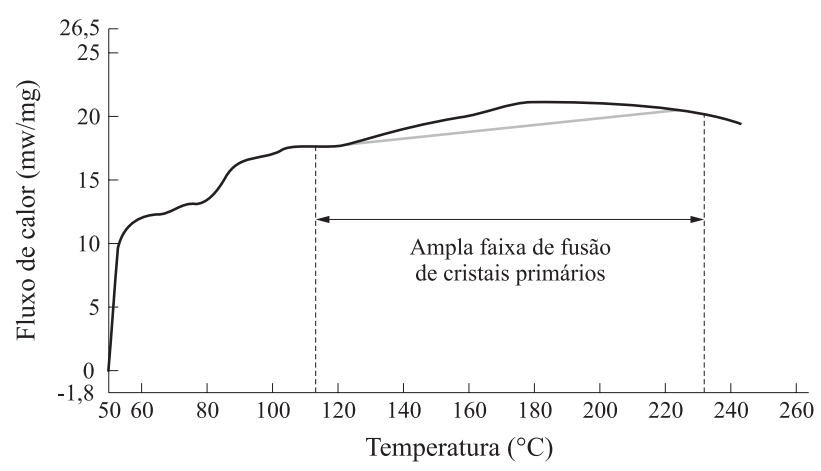

Figura 8. Termograma de DSC para composto de PVC não processado

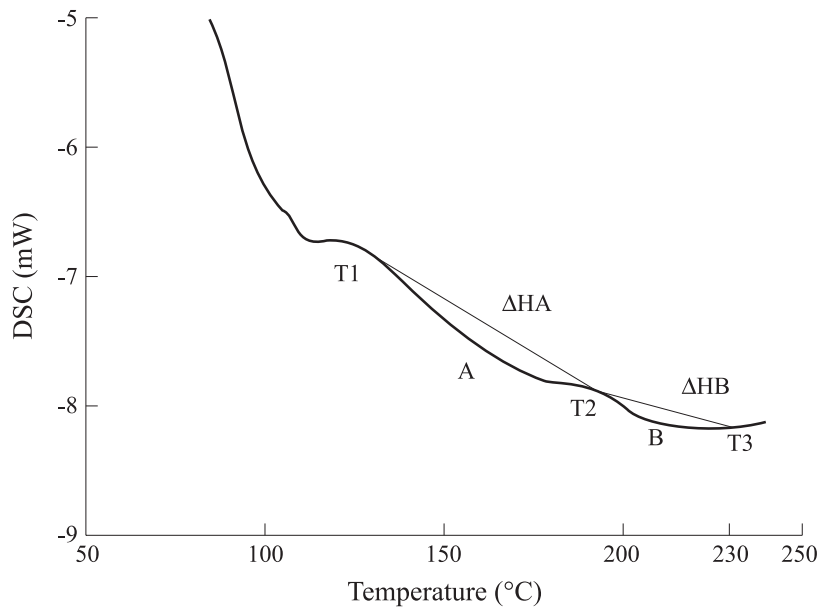

Figura 9. Termograma de DSC para um composto de PVC processado

O pico B, que ocorre em temperaturas mais elevadas, é conseqüência da fusão dos cristais primários formados durante a polimerização e que são cristais originalmente lamelares. $\mathrm{O}$ pico A, por sua vez, que ocorre em mais temperaturas mais baixas, representa a fusão dos cristais secundários, gerados durante o resfriamento de amostras já processadas. Estes cristais possuem uma estrutura de micela franjada.

A temperatura $\mathrm{T} 2$, que ocorre exatamente entre o final do pico A e início do pico B, deve ser considerada uma medida direta da máxima temperatura de fusão alcançada durante o processamento $^{[8]}$.

Estando o processo de gelificação relacionado com a destruição dos cristais primários formados durante a polimerização, quanto maior o grau de gelificação e também a temperatura de processamento maior será esta destruição e menor será a área do pico B. O processo de gelificação também está relacionado com a formação dos cristais secundários, os aumentos do grau de gelificação e da temperatura de processamento tendem a aumentar a formação dos cristais secundários e aumentar a área do pico $\mathrm{A}$.

Segundo Fillot ${ }^{[8]}$, sendo a área do pico A correspondente a variação de entalpia $\Delta \mathrm{H}_{\mathrm{A}}$ e sendo a área do pico $\mathrm{B}$ correspondente à variação de entalpia $\Delta \mathrm{H}_{\mathrm{B}}$, a razão de entalpias fornece o grau de gelificação através da expressão da equação 1.

$$
\% \text { Gelificação }=\frac{\Delta H_{A}}{\Delta H_{A}+\Delta H_{B}}
$$

\section{Avaliação do grau de gelificação através de reometria capilar}

Através de ensaios utilizando um reômetro capilar, é possível fazer a correlação entre a gelificação e as propriedades tanto viscosas como elásticas do material, por exemplo, inchamento do extrudado, fratura do fundido e variação de pressão na entrada do capilar ${ }^{[10]}$.

O rêometro capilar funciona da seguinte maneira: primeiramente coloca-se o polímero a ser analisado, no caso o composto de PVC, no barril do reômetro. Este sofre um aquecimento, em seguida começa a ser pressionado por um pistão com uma velocidade de descida controlada, o que possibilita o controle da vazão volumétrica (Q) do fluido. O escoamento do material se dá através de um capilar com dimensões conhecidas.

Segundo Fujiyama e Kondou ${ }^{[10]}$, a forte influência da gelificação nas propriedades viscosas e elásticas durante fluxo é uma característica do PVC não observada para outros termoplásticos no estado fundido.

Com o aumento da temperatura e do grau gelificação ocorre uma mudança no fluxo (ou escoamento) dos grãos da resina de PVC que se deslizam umas nas outras até atingir um estado de fluxo uniforme de moléculas emaranhadas. Pode-se dizer que em altas temperaturas, com o processo de gelificação bem desenvolvido e um fluxo uniforme, a viscosidade torna-se alta, bem como a elasticidade do fundido, observada através o inchamento do extrudado, e da fratura do fundido.

Na Figura 10 observa-se um esquema de fluxo no reômetro capilar e o perfil de variação de pressão $\Delta \mathrm{P}$ ao longo do reômetro. A variação de pressão $\Delta \mathrm{P}$ nada mais é que a soma da pressão quando o material deixa o reservatório ou barril (cujo diâmetro é grande) e passa para o capilar (cujo diâmetro é pequeno) $\mathrm{P}_{\text {entrada }}$ mais a pressão ao longo do capilar $\mathrm{P}_{\text {capilar }}$ cujo comprimento é $\mathrm{L}$.

Com o aumento da temperatura de processamento em compostos rígidos de $\mathrm{PVC}$, a pressão na entrada do capilar $\mathrm{P}_{\text {entrada }}$
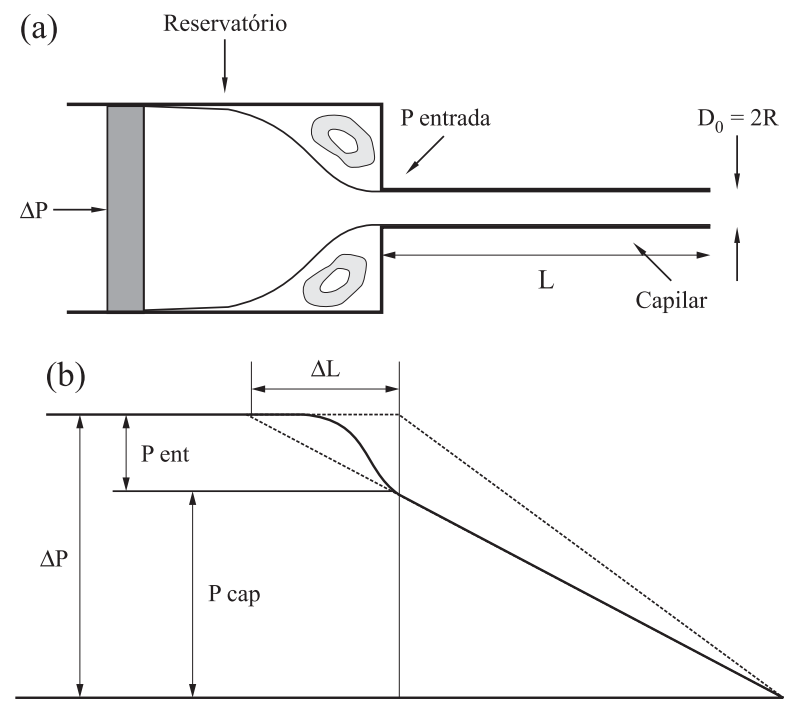

Figura 10. (a) Esquema de fluxo no reômetro capilar; (b) variação de pressão $\Delta \mathrm{P}$ ao longo do reômetro 
também aumenta já que se tem uma mudança de escoamento de partículas para escoamento de moléculas emaranhadas apresentando este fluxo uma energia elástica armazenada na entrada do capilar muito mais elevada ${ }^{[10]}$. A energia elástica armazenada também está relacionada com a homogeneidade do composto fundido, quanto mais homogêneo está o composto mais energia elástica é armazenada e também maior será a pressão na entrada do capilar. O processo de gelificação é fundamental para a obtenção de um fundido homogêneo. Aumentando-se o grau de gelificação do composto, aumentase a homogeneidade do composto fundido, aumentando a energia elástica armazenada tendo-se, portanto uma pressão na entrada do capilar maior. Portanto é possível quantificar o grau de gelificação de um composto de PVC em função da pressão de entrada no capilar.

A Figura 11 exibe uma curva da variação da pressão na entrada do capilar em função da temperatura de processamento para o escoamento de um composto de PVC.

O grau de gelificação pode ser calculado em função da pressão de entrada medida para a amostra a ser analisada, da pressão mínima de entrada para baixas temperaturas e a pressão máxima de entrada para elevadas temperaturas ${ }^{[1]}$, de acordo com a expressão da equação 2 .

$$
\% \text { Gelificação }=\frac{P_{\text {Entrada }}-P_{\min }}{P_{\max }-P_{\min }}
$$

A Figura 12 apresenta o grau de gelificação em função da temperatura de processamento

A reometria capilar também é utilizada para analisar a correlação existente entre a gelificação e o fenômeno de inchamento do extrudado durante o processo de extrusão. Ao ser deformado por cisalhamento entre as paredes do capilar do rêometro, o polímero tem suas cadeias orientadas na direção do fluxo, ao mesmo tempo em que esta massa polimérica tenta recuperar essa deformação elástica ainda dentro da matriz. Assim, as moléculas da massa polimérica fundida tendem a retornar ao seu estado de equilíbrio enrodilhado, porém só conseguem recuperar parcialmente a deformação sofrida durante sua passagem pelo capilar. Sempre permanece uma parcela de deformação que só será recuperada após a saída do capilar. A recuperação da deformação elástica da massa

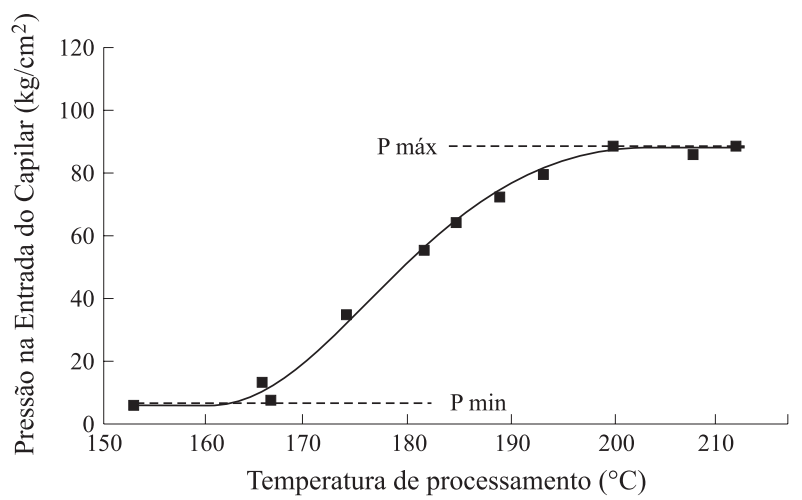

Figura 11. Variação da pressão de entrada no capilar $\left(\mathrm{kgf} / \mathrm{cm}^{2}\right) \mathrm{com}$ a temperatura de processamento $\left({ }^{\circ} \mathrm{C}\right)$ para um composto de PVC

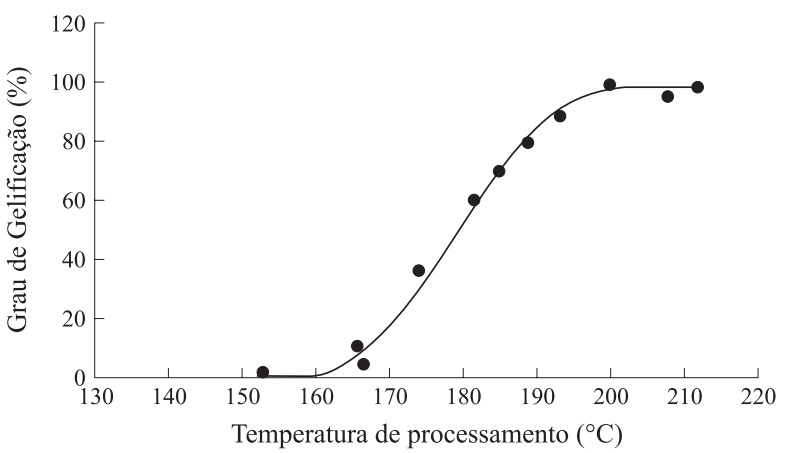

Figura 12. Variação do grau de gelificação (\%) em função da temperatura de processamento $\left({ }^{\circ} \mathrm{C}\right)$

polimérica sofrida dentro do capilar faz com que as moléculas se desorientem fora do capilar e se enrodilhem novamente. Este tipo de recuperação ou relaxação molecular proporciona um aumento no diâmetro ou na espessura do extrudado saindo do capilar como se ocorresse um inchamento. Portando o inchamento do extrudado pode ser quantificado pela razão entre o diâmetro do extrudado (D), sobre o diâmetro do capilar $\left(\mathrm{D}_{0}\right)$ ou da matriz circular no caso da extrusora,

Para resinas poliolefínicas, como no caso de polietileno e de polipropileno, esperada-se que com o aumento da temperatura o inchamento do extrudado diminua em baixas taxas de cisalhamento, pois os polímeros que são extrudados em altas temperaturas, apresentam facilidade de se deformarem e de recuperar grande parte da deformação elástica sofrida dentro do capilar, tornando muito pouco o que resta para recuperar fora deste ${ }^{[12]}$.

$\mathrm{O}$ fato do inchamento do extrudado $\left(\mathrm{D} / \mathrm{D}_{0}\right)$ aumentar com o aumento da temperatura de extrusão é uma característica exclusiva do $\mathrm{PVC}^{[10]}$, pois aumentando-se a temperatura e o tempo de fluxo sob extrusão, o grau de gelificação aumenta. Como conseqüência ocorre uma mudança na morfologia e no tipo de fluxo, pois com a evolução da gelificação e da fusão, a estrutura e o fluxo de partículas escorregando umas sobre as outras se torna um fluxo de moléculas emaranhadas que escorregam umas sobre as outras, tornando o fluxo mais deformável elasticamente no estado fundido. Quanto maior o grau de gelificação, maior será a deformação elástica sofrida dentro do capilar e, consequentemente maior será a deformação recuperada fora da matriz, aumentando o grau de inchamento do extrudado.

A fratura do fundido é um fenômeno que ocorre durante a extrusão de um polímero fundido decorrente de efeitos elásticos destes polímeros durante seu escoamento. Este fenômeno se manifesta em forma de distorção grosseira do extrudado ao sair da matriz ou de um capilar. Quando a massa polimérica passa de regiões mais amplas, ou seja, de seções transversais mais largas para outras regiões mais estreitas, ocorre uma elevação localizada de energia de deformação do fluído escoando nesse ponto de convergência ${ }^{[12]}$, aumentando a tensão de cisalhamento e a taxa de cisalhamento nas paredes desta região. Os aumentos bruscos de tensão e taxa de cisalhamento faz com que as moléculas da massa fundida em contato com as paredes se deformem elasticamente em um 
nível muito superior aquelas que se encontram mais afastadas das paredes desta região. Esta diferença significativa de deformação imposta pelo fluxo convergente pode gerar um distúrbio no fluxo da massa fundida proporcionando distorções no extrudado. O grau de distorções torna-se significativo acima de certa tensão e taxa de cisalhamento. Assim, se a tensão e a taxa de cisalhamento se tornar acima de um valor crítico, a fratura do fundido ocorrerá.

Se a gelificação do PVC for insuficiente, tem-se um fluxo de partículas escorregando-se umas sobre as outras, consequentemente a energia elástica armazenada na entrada do capilar, ou seja, na seção convergente do fluxo, é muito pequena e com isso a fratura do fundido não ocorre tão facilmente ${ }^{[10]}$. Com o aumento do grau de gelificação do PVC tem-se uma mudança de fluxo que passa a ser de moléculas emaranhadas escorregando-se umas sobre as outras, e com isso a energia elástica armazenada na entrada do capilar passa a ser muito maior, sendo mais fácil de ocorrer à fratura do fundido.

\section{Avaliação do grau de gelificação através de reometria rotacional}

A reometria rotacional também pode ser utilizada para quantificar o grau de gelificação de resinas de PVC. Este tipo de reômetro opera com taxas de cisalhamento menores que as desenvolvidas na extrusora e a medida das propriedades reológicas é realizada a partir da imposição de um fluxo de arraste à massa polimérica. Este fluxo é imposto pela rotação, no caso de fluxo permanente sob cisalhamento, ou através de oscilação. Em ensaios de regime oscilatório é possível separar a contribuição elástica da viscosa na propriedade total do polímero em relação ao tempo ou a freqüência ${ }^{[13]}$. Para que a análise dos resultados seja válida, os testes devem ser realizados dentro do regime viscoelástico linear, ou seja, utilizando amplitude das tensões (ou deformações) suficientemente pequenas, de modo que a resposta (tensão ou deformação) tenha a mesma forma que a solicitada. Mesmo com a limitação de não poder medir propriedades reológicas em médias e altas taxas de cisalhamento, esse tipo de reometria permite realizar uma caracterização reológica completa do polímero submetido à deformação sob cisalhamento, sendo possível correlacionar os resultados à estrutura molecular do mesmo ${ }^{[14]}$.

A determinação do regime viscoelástico linear para um composto de PVC a uma dada temperatura é feita fazendo-se uma varredura de tensão ou deformação a uma freqüência constante.

Considerando-se um fluxo em que a deformação de cisalhamento $\gamma$ varia com o tempo de forma senoidal, tem-se a relação expressa na equação 3 :

$$
\gamma_{\mathrm{yx}}(\mathrm{t})=\gamma_{\mathrm{o}} e^{i \omega t}
$$

Onde $\omega$ é a freqüência, $\gamma_{0}$ é a amplitude de freqüência positiva e $\mathrm{e}^{\mathrm{iwt}}=\cos (\omega \mathrm{t})+\mathrm{i} \operatorname{sen}(\omega \mathrm{t})$. A tensão de cisalhamento $\tau$ oscilará com a mesma freqüência, mas estará fora de fase:

$$
\tau_{\mathrm{yx}}(\mathrm{t})=\tau_{\mathrm{o}} e^{i(\omega t+\delta)}
$$

Sendo $\tau_{0}$ a amplitude de tensão de cisalhamento positiva e $\delta$ o ângulo de fase relativo à deformação. Relacionando-se a tensão de cisalhamento e a deformação por cisalhamento e dividindo-se a equação (3) pela (4), tem-se:

$$
G^{*}=\frac{\tau_{\mathrm{yx}}(\mathrm{t})}{\gamma_{\mathrm{yx}}(\mathrm{t})}=\frac{\tau_{0}}{\gamma_{0}} e^{i \delta}=\frac{\tau_{0}}{\gamma_{0}} \cos (\delta)+i\left[\frac{\tau_{0}}{\gamma_{0}} \operatorname{sen}(\delta)\right]
$$

Sendo $G^{*}$ denominado de módulo complexo em cisalhamento, que também pode ser representado pela equação:

$$
G^{*}=G^{\prime}+\mathrm{iG}^{\prime}=\mathrm{G}^{\prime}+\mathrm{G}^{\prime \prime}
$$

Sendo G' o módulo de armazenamento em cisalhamento, associado à componente em fase com a deformação, ou seja, está associado à contribuição elástica ou armazenamento de energia em cada ciclo, e G” o módulo de perda em cisalhamento, associado à componente fora de fase com a deformação, ou seja, à contribuição viscosa ou dissipação de energia em cada ciclo.

A razão entre G" e G' é chamada de tangente do ângulo de fase $\delta$, também conhecida como coeficiente de amortecimento $(\tan \delta)^{[14]}$.

$$
\tan \delta=\frac{G^{\prime \prime}}{G^{\prime}}
$$

No caso particular do PVC, para baixas temperaturas, tem-se uma diminuição da elasticidade, caracterizada pela componente G', e também uma diminuição dos efeitos viscosos, caracterizados pela componente G". Hinrichsen e Thorsteinsen ${ }^{[15]}$ ensaiaram algumas amostras de compostos de PVC no reômetro rotacional em regime oscilatório ou dinâmico sob cisalhamento e observaram que com o aumento do grau gelificação e para temperaturas abaixo da temperatura de processamento a razão entre o módulo elástico ou de armazenamento sob cisalhamento G' e o módulo de perda G” aumenta, ou seja, o $\tan \delta$, diminui.

Para temperaturas acima da temperatura de processamento, a razão G' e G" diminuem, portanto o tan $\delta$ aumenta.

Por outro lado, para baixas temperaturas, ou seja, inferiores a temperatura de processamento, os valores de $\tan \delta$ são relativamente baixos. Assim, à medida que a temperatura de ensaio ultrapassa a temperatura de processamento os valores de $\tan \delta$ aumentam significativamente.

\section{Teste de imersão em cloreto de metileno para avaliar o grau de gelificação de resinas de PVC}

A homogeneidade das propriedades mecânicas e suas variações ao longo do comprimento de produtos extrudados de PVC dependem da homogeneidade da gelificação que pode ser avaliada através do teste em cloreto de metileno. O teste consiste em imergir uma amostra de produto final de PVC rígido no cloreto de metileno e este tende a atacar quimicamente a amostra.

Dependendo da temperatura de processamento, os produtos de PVC apresentam vários níveis de resistência ao cloreto de metileno. Amostras de PVC processadas em diferentes 
condições, apresentam diferenças significantes quanto à resistência química a solventes como o cloreto de metileno e a conclusão alcançada é que esta resistência química ao cloreto de metileno, por exemplo, está fortemente relacionada com o processo de gelificação.

Se o grau de gelificação do composto de PVC for elevado, sua resistência ao cloreto de metileno também será alta, sofrendo apenas um inchamento uniforme. Porém, se o composto de PVC apresentar um reduzido grau de gelificação, a imersão deste composto no cloreto de metileno provocando a separação das partículas primárias que estão apenas parcialmente sinterizadas, sendo, portanto fortemente atacado e apresentando baixa resistência química a este solvente ${ }^{[5]}$.

$\mathrm{O}$ aquecimento não homogêneo do polímero, bem como o transporte não estável do polímero fundido nos canais da rosca e na matriz da extrusora pode originar instabilidades no processo de extrusão e estas instabilidades podem gerar variações locais no grau de gelificação.

O grau de gelificação na camada central, ao longo da espessura, do tubo de PVC deve ser de 4 a $10 \%$ menor que em camadas mais externas do tubo. $\mathrm{O}$ teste de cloreto de metileno traz resultados satisfatórios para graus de gelificação entre $45-50 \%{ }^{[16]}$

Uma importante limitação do teste de imersão em cloreto de metileno é que este não pode diferenciar amostras que alcançaram elevado grau de gelificação; a razão é que o cloreto de metileno não produz um ataque superficial para graus de gelificação acima de um grau moderado ${ }^{[17]}$.

Johansson $^{[17]}$, durante sua pesquisa, utilizou a combinação de irradiação de elétrons com o teste de cloreto de metileno e concluiu que com esta combinação o mesmo se estendeu para amostras com elevado grau de gelificação. A irradiação de elétrons que é realizada em um microscópio eletrônico de varredura causa certo dano à amostra que a torna mais susceptível ao ataque do cloreto de metileno. Amostras com elevado grau de gelificação são altamente resistentes a este solvente e após uma pequena dose de irradiação se tornem menos resistentes.

\section{Conclusão}

Durante o processamento ou transformação em produto, quando aquecida a resina de PVC sofre um processo de gelificação e fusão. Antes de ocorrer a fusão completa da resina de PVC durante seu processamento, uma etapa conhecida como gelificação acontece e é fundamental para que a resina torne-se uma massa fundida e processável.

A identidade dos grãos, das partículas primárias bem como a região cristalina é destruída durante o processo de gelificação e fusão. Com o resfriamento, após a fusão, a resina processada passa a ter uma morfologia completamente diferente daquela original. $\mathrm{O}$ grau de gelificação é um parâmetro muito importante já que irá influenciar significativamente as propriedades mecânicas do produto final. Produtos de PVC podem apresentar ótimo desempenho mecânico com graus de gelificação não muito elevados. A influência da morfologia na gelificação pode ser analisada por técnicas capazes de monitorar a evolução da morfologia e o comportamento de gelificação e fusão com graus de complexidade diversos.

\section{Referências Bibliográficas}

1. Moghri, M; Garmabi, H. - J.Vinyl Addit.Technol, 9, p.81 (2003)

2. Marques, P. R.; Covas, J. A. - Companhia Industrial de Resinas Sintéticas, Cires S.A., 33 páginas(2003) (www.cires.pt/grupocires/home.nsf/ W W W C i r e s E n g D o w n 1 o a d s/ 1ABC447042DA3E5A80256DC5004115ED/\$FILE/ cires\%20PVC2.pdf.) (acessado em Junho 2006)

3. Fumire, J. - "DSC-Gelation Measurement: Influence of PipeFormulation on Result". in: PVC 2005, Brighton (www.solvinpvc.com/static/wma/pdf/3/7/2/3/ Conférence\%20Brighton\%20J.\%20Fumire\%201.pdf.) (acessado em Junho 2006)

4. Allsopp, M. W. - Imperial Chemical Industries Limited. M. W. Allsopp, "Mechanism of Gelation of Rigid PVC During Processing", Imperial Chemical Industries Limited, Herts, UK, (1982).

5. Rodolfo Jr. A.; Nunes, L. R.; Ormanji, W. - "Tecnologia do PVC”, 2a edição. ProEditores, São Paulo (2006).

6. Tomaszewska, J.; Sterzynski, T; Piszczek, K. - J. Appl. Polymer Sci. 93, p. 966 (2004).

7. Vanspeybroeck,Ph. - "Determination of the degree of Gelation of PVC-U using a DSC", in: PVC Technology Conference, Loughborough (2003)(www.pvc4pipes.org/ documents/files/PXII/posters/Vanspeybroeck.pdf) (acessado em junho 2006).

8. Fillot, L. A.; Gauthier, C.; Hajji, P.- "DSC Technique: a powerful Tool to Characterize PVC Gelation". in: The 9th International PVC Brington Conference: PVC 2005, Brighton (2005).

9. Gilbert, M.; Vyvoda, J.C. - Polymer, 22, p. 1134 (1981).

10. Fujiyama, M.; Kondou, M. - J. Appl. Polymer Sci., 90, p. 1808 (2003)

11. Fillot, L. A.; Gauthier, C.; Hajji, P. - "Latest developments in PVC Gelation assessment", in: PVC Technology Conference, Loughborough (2003).

12. Manrich, S. - "Processamento de Termoplásticos", Artliber, São Paulo (2005).

13. Canevarolo, S. V. C. - "Técnicas de Caracterização de Polímeros", Artliber, São Paulo (2004).

14. Bretas, R. E. S.; D’Avila, M. A. - "Reologia de Polímeros Fundidos", EDUFSCAR, São Carlos (2000).

15. Hinrichsen, E. L.; Thorsteinsen, P. J. -J.Vinyl Addit.Technol., 2, p. 18 (1996).

16. Piszczek, K.; Sterzynski, T. T.; £ukaszewicz, E. - Polymer Testing, 22,\p. 115 (2003).

17. Johansson, L. - Polymer Testing, 6, p. 279 (1986). 